\title{
- Observations of meteotsunami on the Louisiana shelf: a lone soliton with a soliton \\ 2
}

3

4

\author{
5 the date of receipt and acceptance should be inserted later \\ A. Sheremet, U. Gravois, and V. Shrira
}

Engineering School For Sustainable Infrastructure \& Environment (ESSIE), 365 Weil Hall, University of Florida, Gainesville, FL 32611

Tel.: +352-294-7811; E-mail: alex.sheremet@essie.ufl.edu

Uriah Gravois

Engineering School For Sustainable Infrastructure \& Environment (ESSIE), 365 Weil Hall, University of Florida, Gainesville, FL 32611

E-mail: uriah@coastal.ufl.edu

Victor Shrira

School of Computing and Mathematics, MacKay Building Room 2.10, Keele University, Staffordshire ST5 5BG

Tel.: +44 (0)1782 733267; E-mail: v.i.shrira@keele.ac.uk 
for meteotsunamis. They were not observed before only because of the scarcity of high-resolution observations. The results highlight the effectiveness of the $\mathrm{vKdV}$ equation in providing understanding of the fundamental mechanisms of the complex natural phenomenon that would otherwise require computationally very expensive numerical models.

Keywords Meteotsunami · Lone soliton · Undular bore · Variable-coefficient Korteweg-de Vries equation

\section{Introduction}

Meteotsunamis are sea-level oscillation in the tsunami time scale band (minutes to hours) generated by atmospheric perturbations, such as squall lines associated with atmospheric gravity waves and frontal passages. A significant of body of evidence exists suggesting the phenomenon is fairly common (for a long list of examples see e.g., Montserrat et al., 2006; Sĕpić et al., 2012), although its instrumental observations are very scarce. In the United States waves of this type have been documented and analyzed on the Great Lakes (Ewing et al, 1954; Bechle et al., 2015), Daytona Beach, FL, meteotsunami of 1992 (Ghurchill et al., 1995), Western Florida shelf meteotsunami of 1995 (Paxton and Sobien, 1998), on the northwestern Atlantic coast (Mercer et al. , 2002), and the Boothbay, MA, meteotsunami of 2008 Vilibić et al. (2104). In some geographic areas these sea-level oscillations occur regularly enough to have acquired specific local names, such as the famous "rissaga" of the Balearic Islands. Atmospheric pressure oscillations are typically small (order of a few Pa) even for the strongest storms, therefore, to generate a significant sea-level response some resonance mechanism has to be active over a relative large area. The most recognized such mechanism is the Proudman resonance (Proudman, 1929), but others are possible (Montserrat et al., 2006), such as the Greenspan (1956) resonance, and the shelf resonance.

Even under the resonance conditions meteotsunamis can reach dangerous magnitudes only if additionally amplified by other processes related to bathymetry and coastal geometry, such as refractive focusing, shoaling, and resonance of enclosed bays (harbors, see e.g., a thorough discussion Montserrat et al., 2006). The famous catastrophic "abiki" event documented and analyzed by Hibiya and Kajiura (1982) illustrates the type of amplification characteristic for the shallow open shelf environments similar to the Atchafalaya shelf. The Proudman resonance is typically effective over the shelf (order of 50-m depth), where the velocity of the atmospheric forcing matches the velocity of the long waves; as the water becomes shallow, shoaling and refractive focusing amplify the perturbation. As shoaling amplification factor for wave height is between $\sqrt[4]{h_{r} / h}$ for linear waves and $h_{r} / h$ for solitary waves, the wave that eventually significantly impacts the shoreline is ultimately shaped by an amalgamation of complex processes such as nonlinearity, breaking and interaction with the oceanographic environment 
(waves, currents, stratification, sedimentary substrate). Because this transformation is forced by the nearshore bathymetry we will refer to this amalgamation of effects as the "nearshore transformation.

The two ends of the meteotsunami life (generation, and the interaction with shoreline), have received most of the scientific attention (e.g., Lynett et al., 2014; Borrero et al., 2015, and many others). Our understanding of the different processes that drive the shoaling transformation, however, is limited.

The dynamics of the initial perturbation and its disintegration into a packet of cnoidal waves evolving into solitons (also called "undular bore", or "solibore"), is well described mathematically, and have been studied in various mathematical and physical contexts ( for the KdV (e.g., Whitham, 1973), for the Boussinesq equation, e.g., Bjørkavåg and Kalisch, 2011; for the Gardner equation Kamtchatnov et al., 2012). One of the reasons for the significant advancement of our understanding of solibore formation on the ocean shelf is the variable-coefficient $\mathrm{KdV}(\mathrm{vKdV})$ equation first derived by Ostrovsky and Pelinovsky (1975). The simplicity and flexibility of the formulation allows one to capture quite accurately the processes of nonlinear shoaling and refractive focusing, with other processes such as various dissipation mechanisms easily incorporated as parameterizations. The usefulness of the equation is illustrated by its ubiquitous use (e.g., Pelinovsky et al., 1993; Caputo and Stepanyants, 2003; Grimshaw, 2007; Grue et al., 2008; Sergeeva et al., 2011; El et al., 2012, and many others).

Other longwave nearshore transformation processes are less understood and have only recently garnered some attention. Examples include tsunami interaction with the sedimentary environment, or background wave fields, (e.g., Liu et al. 2007; Tian et al. 2015). Studying the role of the oceanographic environment in the nearshore transformation of (meteo)tsunamis is difficult because it requires capturing a rare and hard to predict event with expensive high-resolution shelf instrumentation, typically deployed for short periods of time and for narrow-focus experiments. In fact, most of the available meteotsunami observations consist of just pressure records from tidal gauges located close to the shoreline with insufficient sampling intervals of 1 or $6 \min ^{1}$. A realistic model of meteotsunami evolution requires atmospheric measurements and numerical capabilities at the squall/convection scale (in the order of $1 \mathrm{~km}$ horizontal scale and $100 \mathrm{~m}$ vertical scale) over the relevant area of the ocean (in the order of $500 \mathrm{~km}$ ). The hydrodynamic part of the problem requires similar information about ocean circulation, bathymetry and coastal geometry. The means for such a broad approach are becoming available in recent years, (e.g., Horvarth and Vilibić, 2014). For example, in the USA, the Hyper Resolution Rapid Refresh (HRRR) models, currently at version 2, with horizontal resolution of $3 \mathrm{~km}$ and 51 vertical layers entered operational use in 2014 (Benjamin et al., 2016).

However, a comprehensive approaches of this kind requires a significant, multidisciplinary effort with access to expensive

1 https://tidesandcurrents.noaa.gov/tsunami 
and complex modeling tools, all of which are outside the scope of this study. Fortunately, the vKdV equation provides an extremely useful mathematical tool for integrating all the effects important for the nearshore transformation (shoaling amplification, refractive focusing/de-focusing, and potentially other processes such as bottom friction, mud-induced dissipation, etc) into a single simple formulation.

Here, we report one of the rare occurrences of the nearshore transformation of a meteotsunami being captured by a highresolution instrument array. The perturbation was generated by the interaction of a atmospheric gravity wave with a strong convective system (Ruppert and Bosart, 2014) that passed over the northeastern Gulf of Mexico on March 7th, 2008. By coincidence at the time of the event, a large field experiment supported by the US Office of Naval Research was in progress on the West Louisiana coast. The experiment was dedicated to the study of wave-current-sediment interaction on shallow muddy shelves (Safak et al., 2010; Sahin et al., 2012; Engelstad et al., 2013). The instrument array included pressure sensors, current profilers, turbidity sensors, salinity and temperature, and others). Observations of wind-wave, currents, and sediment transport were collected in shallow water (depths less than $15 \mathrm{~m}$ ) at wind-wave sampling rates of $2 \mathrm{~Hz}$ or higher, and spanning the entire water column, as well as tens of kilometers in the along- and cross-shore. The data set provides, we believe, an unprecedented detailed description of the nearshore transformation of a meteotsunami, including the disintegration into solitary wave trains, dissipation and interaction with the muddy bed, as well as associated sediment transport and bed reworking processes.

While the wealth of information collected can be used for future studies on the interaction between a meteotsunami and the oceanographic environment, this study focuses on a particularly intriguing (at least for the authors) feature of the event: in addition to the expected meteotsunami manifested as an undular bore, i.e. a train of cnoidal waves, every observation site also recorded a robust lone soliton, also a element of the meteotsunami but largely disconnected from the undular bore. At some locations the soliton was observed near the crest of a longer perturbation; at others, it preceded the arrival of the solibore by approximately 5 minutes. This lone soliton was quite spectacular, as it was $1.5-\mathrm{m}$ high, propagated though a wind-wave field not exceeding $0.2 \mathrm{~m}$ in height, and reached the observation sites far ahead of the trailing solibore. Meteotsunami occurrences are well documented; the process of breaking of a large scale wave into a solibore has been observed before (e.g., Anders Grawin(@ now famous images of the 2004 Sumatra tsunami), and is well understood; while lone solitons of this magnitude have never been reported, probably because of the lack of measurements of adequate resolution; however, they are not completely unexpected. The phenomenon of disintegration of a long wave perturbation into a sequence of solitons is well known in the general context of the nonlinear wave theory (e.g., Whitham, 1973): depending on the ratio of parameters 
characterizing nonlinearity and dispersion of the initial perturbation called the Ursell number the general theory predicts a

large number of solitons or a solibore for large values of the Ursell number, or a single soliton for small Ursell numbers; but under no circumstances the theory allows for the coexistence of collocated lone soliton with a solibore. To our knowledge nowhere in nature observations of a solibore collocated with an apparently unrelated lone soliton has ever been reported. The aim of this work is to report detailed observation of precisely this seemingly improbable phenomenon, with its incompatible constituent parts belonging to two very different contexts, a sphinx; to elucidate the physical mechanisms making it happen and to understand its place in the general context of meteotsunamis.

The paper is organized as follows. In Section 2 we present the data sources, including the layout of the oceanographic experiment field experiment. The field observations are discussed in the same section. Section 3 describes a reconstruction of the propagation of the meteotsunami, based on the oceanographic and meteorological observations. In Section 4 we present the mathematical model based upon vKDV and discuss the simulation results. The results are summarized and discussed in Section 5 .

\section{Data Sources and Methods}

The observations discussed here were collected between February and April, 2008, on the muddy inner shelf fronting Atchafalaya Bay, Louisiana, USA (Figure 1). The 2008 experiment on wave-mud interaction, initiated and funded by US Office of Naval Research, instrumented two sites: a site located on the subaqueous clinoform of the Atchafalaya River (hereafter called the "East site"; see e.g., Jaramillo et al. 2009; Safak et al. 2010; Sahin et al. 2012), and a site located to the west of the Atchafalaya Bay, on the Louisiana chenier plain ("West site", e.g., Engelstad et al. 2013). The West Louisiana shelf was chosen for the experiment because of the dominance of cohesive sediments (mud and silt), with about $17 \%$ fine sand content (Jaramillo et al., 2009). The shelf is characterized by a very mild slope (mean slope $\simeq 10^{3}$ or less; the 10 -m isobath is approximately $40 \mathrm{~km}$ offshore). While most of the year the Gulf of Mexico is not an active wave environment, in winter and early spring cold-front passages, occurring with a periodicity of one to two weeks (Hardy and Hsu , 1997; Thompson et al. , 2013), generate substantial wave activity, with wave heights in excess of $2 \mathrm{~m}$, and swell periods of 8-10 s. These waves are strong enough to mobilize bed sediment layers of thickness of over $30 \mathrm{~cm}$ (Sahin et al., 2012).

The East site, instrumented by University of Florida in collaboration with Tulane University, comprised four instrument clusters located near the 7-m, 5-m, and 4-m isobath fronting the Atchafalaya Bay. Three platforms (number 1-3 in Figure 1) 
were deployed on a cross-shore transect spanning $8 \mathrm{~km}$; platform number 4 was located approximately $20 \mathrm{~km}$ to the West near the 4-m isobath. With slight variations, all clusters were built around a pair of current profilers. A high-resolution profiler (PCADP, Sontek 1.5 MHz Pulse Coherent Acoustic Doppler Profiler) was mounted looking down, sampling at 2 Hz continuously in 27 bins of $3.2 \mathrm{~cm}$ with a 30-cm blanking distance, and logging measurements of conductivity, temperature and suspended sediment concentration measurements at the same rate. The other profiler, mounted looking up (RDI Workhorse ADCP) had coarser resolution recorded 10-min averages of velocity sampled at $2 \mathrm{~Hz}$ in $5-6$ measurement bins (bin height $50 \mathrm{~cm}$, blanking distance $45 \mathrm{~cm}$ ). Both profilers were equipped with pressure sensors and additional pressure sensors were mounted on the platform. Details of the East site instrumentation are given in Sahin et al. (2012).

The West site, located approximately $100 \mathrm{~km}$ to the west of the east sites, was instrumented through a collaboration between the Naval Postgraduate School and Woods Hole Oceanographic Institute (see Engelstad et al., 2013). Instruments were deployed at 16 locations distributed in two cross-shore arrays spanning approximately $12 \mathrm{~km}$, depths ranging from $20 \mathrm{~m}$ to $5 \mathrm{~m}$, and one alongshore array spanning approximately $22 \mathrm{~km}$. The arrays included two surface-following directional Waverider buoys (sampling in 68-minute bursts at $2 \mathrm{~Hz}$ every four hours), eight Setra 270 capacitance-type pressure gauges (2-Hz continuous sampling) and six Nortek ADV velocity meters (burst sampling), bottom-mounted at approximately 70 and $170 \mathrm{~cm}$ above the seabed respectively.

For simplicity, the data presented here are based only on pressure time series. All acoustic sensors deployed at the East site (PC-ADP, ADCP, and acoustic Doppler velocimeters) included pressure sensors. A low-pass Fourier filter was applied to all $2 \mathrm{~Hz}$ pressure records using a frequency cutoff of $1 / 300 \mathrm{~Hz}$. The filtered time series was then interpolated to a 30 s resolution time series, converted hydro-statically to water elevation and taken as the observed tide. Predicted tides were extracted using the Tidal Inversion Software ${ }^{2}$ ) developed by Egbert and Erofeeva (2002) and driven by Tidal Model Driver ${ }^{3}$. Phases and amplitudes for eight primary harmonic tidal constituents (M2, S2, N2, K2, K1, O1, P1, Q1) were used to construct predicted tide time series on the same time axis as observed tide.

The bathymetric grid for Louisiana and Texas coastal and offshore waters used here was developed from National Oceanic and Atmospheric Administration (NOAA) Electronic Navigation Charts (ENCs). The Geospatial Data Abstraction Library (GDAL, http://www.gdal.org) was used to extract depth contours and point soundings from ENCs, to which a regular grided

\footnotetext{
2 http://volkov.oce.orst.edu/tides/

3 http://polaris.esr.org/ptm_index.html
} 
surface was subsequently fitted. The bathymetry constructed via this method compared better with the measured depths at field sites compared to all other bathymetry sources examined.

Radar reflectivity values are based on the NOAA Level III NEXRAD observations collected by the station at Lake Charles, Louisiana, and archived by the National Climatic Data Center ${ }^{4}$. The published data were processed using the netcdf java toolbox ${ }^{5}$ developed by the University Cooperation for Atmospheric Research (UCAR). The position of the maximum radar reflectivity was digitized manually and used to generate smooth estimates of both position and speed of the squall line associated with the front.

\section{Observations}

\subsection{Oceanographic data}

Examples of de-tided time series observed at the West and East sites during the storm of Match 7, 2008 are shown in Figure 2. Both sites show significant variations of surface elevations on time scales in the order of 10 min and longer, as well as the presence of solitons with a characteristic time scales comparable to that of swell (order of $10 \mathrm{~s}$ ).

An example of the observations from the West site array (only 3 instruments) is shown in Figure 2, left panels. Untangling the data collected by the East array is complicated by the shape of the array and the local essentially two-dimensional bathymetry, with Trinity Shoal causing an significant submerged embayment at the level of the 5-m isobath (Figure 1). The time series presents a complicated picture, with distinct meteotsunami waves arriving at different times, depending on the position of the sensor with respect to the trajectory of the squall line and the local bathymetry. A more careful analysis (not shown) suggests the presence of two large-scale waves (of order of $10 \mathrm{~min}$ ) refracting and overlapping at various phases. For example, at sensor P03 two crests of approximately 0.5-m height arrive at about 4:50 hr and 5:00 hr, local time (Figure 2 panel P03). All instruments also recorded the presence of a lone soliton of 0.8-m height. In Figure 2, left panels, the lone soliton arrives slightly ahead of the crest of the second large-scale wave, but there is no observable undular bore structure that one could associate the lone soliton with.

With a nearly laterally uniform bathymetry, the East site has a simple geometrical layout, and the observations have the advantage of containing a wealth of information about other processes (e.g., sediment transport, see Sahin et al. 2012). In

\footnotetext{
4 http://www.ncdc.noaa.gov/

5 http://www.unidata.ucar.edu/downloads/netcdf/netcdf-java-4/index.jsp
} 
contrast to the West site observations, at locations of sensors N1 and N2 the time series are dominated by a single large-scale wave of approximately $0.5-\mathrm{m}$ height. The main wave arrives at sensor N1 at approximately 6:00 hr, followed by two shorter and smaller waves arriving at 6:05 $\mathrm{Hr}$ and 6:15 hr. The large perturbation that seems to arrive at 6:15 hr at $\mathrm{N} 1$ is in fact an artifact. An inspection of the time series recorded at N1 (Figure 2, panel N1) indicates a significant variation in the data recorded by different instruments (the PC-ADP, the ADCP, and the stand alone Paros pressure sensor), suggesting that the meteotsunami impact caused the instrument platform to tilt over by 30 degrees. This is confirmed by the ADCP compass record of heading, pitch and roll.

The meteotsunami arrived at the East sit approximately 100 min after the squall passed over the site (Figure 3) An important element of the East site observations is the presence of a well defined solibore (Figures 2 and 3 ). The solibore arrives at sensor N1 the process of its disintegrating into a soliton train, whose development over the span of East site array is well captured by the PC-ADP pressure sensors at N1 and N2 (Figure \ref\{fig: ts \}). A lone soliton of approximately 1.2-m height is also observed, preceding the main wave by approximately $5 \mathrm{~min}$. The presence of the soliton is all the more fascinating as the it must have appeared to a local observer as if coming out of nowhere, long before the main meteotsunami waves arrived, and propagating through a wave field of barely $20-\mathrm{cm}$ height. As we've already mentioned, the coexistence of collocated single soliton and and an solibore contradicts the existing understanding, at least at first glance.

The fact that a lone soliton was recorded by all instruments, spanning an coastal length of approximately $150 \mathrm{~km}$ is also rather surprising. The analysis that follows is an attempt to understand the physics of such a phenomenon, to understand how the lone soliton and the trailing solibore could have been observed at the same place almost simultaneously. We also note that although a front always generates both free and forced wave components, in our case the forced wave component moving with the squall is negligibly small: the pressure sensors registered no discernable signal when the front passed over the site (Figure 3)

Qualitatively, the mechanism of generation of a lone soliton is not a mystery: lone solitons are in fact a degenerate form of weak solibores, thus are products of the same disintegration process. It is well known that in the KdV (Korteweg-de Vries) framework, an arbitrary hump-like perturbation disintegrates into a solibore and a dispersive wave train (e.g., Whitham, 1973). For the non-dimensional KdV equation

$$
u_{t}+u u_{x}+\frac{1}{\sigma^{2}} u_{x x x}=0, \text { with } u(x, 0)=\phi(x)
$$


where $\sigma$ is the Ursell parameter. The number of solitons $N$ generated by an initial perturbation being at least partly positive, i.e. satisfying $\int_{-\infty}^{\infty} \phi(x) d x>0$, with the integration is carried out only for those $x$ where $\phi(x) d x>0$, is $N=\frac{\sigma}{\pi \sqrt{6}} \int_{-\infty}^{\infty} \phi(x) d x$. For example, for $\phi(x)=\operatorname{sech}^{2}(x)$ (e.g., Whitham, 1973)

$$
N=\llbracket \frac{1}{2}\left(1+\sqrt{1+\frac{2}{3} \sigma^{2}}\right) \rrbracket
$$

where $\llbracket x \rrbracket$ is the entire part of $x$. Under this normalization, for a soliton the Ursell parameter is $\sigma_{s}=\sqrt{12}$. Initial perturbations characterized by $\sigma<\sigma_{s}$ will generate a single soliton. In general, the recipe for generating a lone soliton seems simple enough: any weak initial perturbation with $\sigma<\sigma_{s}$ produces only a single soliton. If, however, $\sigma \gg \sigma_{s}$ the number of the resulting solitons is very large and at not to large times a solibore pattern emerges. A perturbation cannot have large and small Ursell parameter at the same time. These considerations are valid for a flat bed only. If the bed is mildly sloped, equation 2 is known to be a good local approximation, suggesting that more solitons (a solibore) can be expected as the water becomes shallower.

The occurrence of independent, collocated solibore and lone solitons is very peculiar in the KdV framework in a single forcing event with a smooth forcing, as is the case of the Atchafalaya context. Such a state could occur only for non-smooth forcing (e.g., El et al., 2009), or if the initial perturbation consists of two independent, well separated pulses. However, there is no obvious reason for a single squall line to have produced such an initial structure.

The following analysis focuses on the East site array because it has a simpler geometry. It worth noting that the East site instrumentation also includes sensors that provided detailed information about bed reworking by waves, and thus potential clues about the wave-dissipation effects of the fine grained sediments of the Atchafalaya shelf, important for future studies.

\subsection{Passage of a Front: NEXRAD Reflectivity Data}

The origin of the meteotsunami is the passage of a cold front that crossed the northern Gulf of Mexico in the morning of March 7, 2008. The large-scale evolution of the atmospheric perturbation is discussed in detail by Ruppert and Bosart (2014). Their analysis focuses mainly on the evolution over land, where atmospheric soundings are readily available. Over the ocean, the only data available is provided by radar stations along the Texas and Louisiana shelf.

A summary of the radar reflectivity observations collected by the NOAA Level III NEXRAD station at Lake Charles is shown in Figure 4. The storm? [Are we speaking about a storm hereor, as I suspect, about much more sharp squall, as it 
follows from your data?] formed near the Texas border around midnight March 7, and moved eastward roughly parallel to the 29 deg latitude until it exited the Gulf over the Atchafalaya River mouth. Overall, the intensity of the system is reflected in the speed (approximately $20 \mathrm{~m} / \mathrm{s}$ ) of its movement across the shallow Atchafalaya basin: the system crossed the Gulf of Mexico from the Texas coast to the Atchafalaya Bay in approximately $5 \mathrm{hr}$. Initially, the front appears to have driven two separate squall lines: a straight northern segment (red line in Figure 4) and curved southern one (blue line). The curved shape of the South line, also known as "bow echo", is indicative of down-drafts associated with strong convective activity and a fast moving squall.

The two lines connected around 2:22 hr forming a mini-frontal system, with the southern line a cold front, and the northern line a warm one. The connection of the two lines produced a "kink", typically indicative of strong rotation and tornado activity. Similar kinks developed and decayed at the northern edge of the warm mini front. According to analysis of radar reflectivity, the warm mini front evolved closer to the shoreline and developed late (see e.g., Figure 4a, at 04:10 hr). In contrast, the cold front developed offshore, and was the most compact and intense. Overall, the system may have been most active between the 50-m isobath and the shoreline.

Based on the digitization of the squall position, the velocity of the squall line was estimated along all the available positions. Figure $4 \mathrm{~b}$ shows the estimated values of the Froude number $F r=U / c$ (where $U$ is the squall speed, and $c=\sqrt{g h}$, with $g$ the gravitational acceleration, and $h$ the local depth). The effectiveness of Proudman forcing falls off fast with the departure from exact resonance $(\mathrm{Fr}=1)$ larger than 5\%. However, the color map in 4 b highlights larger tolerance margin, i.e., values $0.85<F r=U / c<1.15$. The larger tolerance should be considered an expression of the uncertainties in the estimation of the squall line speed $U$, rather than a straightforward application of the Proudman-resonance physics.

Figure 4b shows several peculiarities. The Proudman resonance domain associated with the northern squall line may have occurred on a narrow band near the shoreline, and may have ceased before 2:00 hr (compare figures Figure 4a and b). The effect of the northern squall on the East site was probably negligible, due to the smaller Proudman resonance region and the sheltering effect of Trinity Shoal. In contrast, due to the different velocities of the different segments of the squall line, the resonance domain of the southern squall likely extended across the shelf, and continued in some segments until 5:00 hr. Finally, due to the distribution of the system velocities along the squall line, the resonance domain of the southern squall line appears to split after 2:22 hr into two separate bands. Both bands have areas that suggest high probability of resonance (green hues, Figure 4b). Note that radar reflectivity data allows for estimating only the position and velocity of the squall line. The 
meteotsunami strength depends on the duration of the resonance, but also on surface wind intensity (data unavailable at the time of writing).

The eastward movement of the southern squall, roughly parallel to the shelf isobaths, and the strong refraction effect of the shelf slope likely caused a continuous shoreward radiation of free waves. The longer time series shown in Figure 3 indicates that the meteotsunami perturbation recorded at the East Site was a free wave, arriving at the site approximately 100 min after the passage of the squall. According to Figure $4 \mathrm{~b}$, over the East site the squall is detuned from resonance by more than $10 \%$. Forced waves recorded at the moment of the squall passage are negligible: platforms N1 and N2 show no detectable signal, while weak oscillations that can be detected in the N4 record, are possibly related to refraction/reflection due to the more complicated local bathymetry. In addition, the squall seemed to have weakened right over the location of the platforms (see gap in reflectivity strength, Figure 4a).

These observations suggest that the East site might have been impacted by two distinct free meteotsunami waves emerging from the two southern resonance bands, somewhere between 3:00 and 4:00 hr. Note that the high-activity kink propagated along the northern band, while the southern band corresponds to the southern tip of the squall line, likely much weaker. This suggests that the wave produced by the southern band was likewise weaker. The two waves probably reached the observation sites via two different paths, characterized by significantly different lengths and local bathymetry. This scenario is consistent with observations: the path of the weaker wave was longer but through deeper waters, and hence, characterized by a larger propagation velocity.

\section{Modeling}

A thorough numerical simulation of the meteotsunami of March 7, 2008, would require as input accurate representations of the atmospheric forcing, and should be capable to describe wave dynamics over the irregular shelf bathymetry covering spatial scales from hundred kilometers (meteotsunami propagation) to tens-to-hundred of meters (soliton). Such a simulation would be hugely expensive, well beyond the scope of this study and not really justified dues to the insufficient data on the atmospheric forcing. While the capabilities of atmospheric models are continuously improving (HRRR models have become available in the USA for operational use since 2014; e.g., Benjamin et al., 2016), a fully-detailed hindcast of the metoceanic conditions that have generated the March 7, 2008 meteotsunami remains a difficult task, well beyond the scope of this study. 
However, a semi-qualitative analysis is still possible, thanks to simple but effective tools such as the vKdV equation. In the past, the $\mathrm{KdV}$ equation and its solitons been often been used as mathematical models for tsunamis. While for the overwhelming majority of tsunamis in the open ocean the soliton model is not realistic (the nonlinearity is so weak that, to form a soliton, propagation distances much larger than the width of any Earth ocean are required Madsen et al. 2008), the situation is radically different for the meteotsunami on the shelf. Solitary waves of various scales are readily formed here with the vKdV equation being indeed the most adequate model. Even if the detailed description of the meteotsunami generation remains unattainable at present, the fundamental physics captured in the vKdV framework provides useful insights into the process.

\subsection{Wave rays}

The use of the vKdV equation in our context is based on the following remarkably fruitful and nontrivial idea. Instead of solving essentially two-dimensional nonlinear inhomogeneous Boussinesq-type shallow water equations, it has been shown by means of a systematic asymptotic analysis employing small nonlinearity assumption that for a relatively smooth bathymetry the fluid motion could be effectively described by a split into a manifold of non-interacting one-dimensional nonlinear equations describing field evolution along the linear ray tubes (Ostrovsky and Pelinovsky, 1975; Engelbrecht et al., 1988). The trick is that when topography is smooth enough to make wave reflection negligible and the WKB approximation applicable, the wave elevation or velocity then depend to leading order on the "running" coordinate along the linear ray tube, which makes the nonlinear effects more important for the along the ray propagation. Hence while the wave evolution is nonlinear, since weakly nonlinear effects are being accumulated as the wave propagates along the ray tube, the process in our case is described by the the $\mathrm{vKdVequation}$, the rays underpinning the $\mathrm{vKdV}$ are to leading order specified by linear eikonal equation. The key small parameters enabling one to employ this asymptotic approach are the smallness of the wavelengths under consideration compared to the characteristic scale of the inhomogeneity of the bathymetry and, crucially, smallness of the nonlinearity (Ostrovsky and Pelinovsky, 1975; Engelbrecht et al., 1988). The nonlinear contributions to wave celerity affect the ray trajectories in the next order, e.g. (Ostrovsky and Shrira, 1976; Engelbrecht et al., 1988).

In our context for a perturbation time scale of $\approx 10 \mathrm{~min}$, the initial spatial wave scale is $\approx 10 \mathrm{~km}$. The depths are roughly in between 10 to $55 \mathrm{~m}$, which yields $\sim 10-25 \mathrm{~m} / \mathrm{s}$ wave speed range. The area of study is characterized by quite mild bottom slopes, of order of $5 \times 10^{-4}$, which shows that the wavelengths are indeed small compared to scale of bottom inhomogeneity. The values of the nonlinearity parameter understood as ratio of characteristic elevation to depth do not exceed $O\left(10^{-1}\right)$. Thus, the situation under consideration falls comfortably within the regimes described by the adopted vKdV and linear rays 
asymptotic model. Linear ray-tracing methods are widely applied for the calculation of tsunami wave propagation path (e.g., Choi et al., 2002and references therein), and often take into account the curvature of the Earth and the Earth rotation. For the problem studied here, characterized by scales in the order of $100 \mathrm{~km}$, the plane geometry provides a sufficiently good approximation. The Earth rotation effects are negligible for the scales under consideration. Here, we use the asymptotic ray method of Ostrovsky and Pelinovsky (1975) to examine the propagation of the meteotsunami on the shelf aiming at explaining the observed unusual pattern: a lone soliton followed by a undular bore. The rays presented here were computed in the MATLAB® programming environment using the MATLAB® ODE solvers.

Figure 5 shows an example of ray calculation. Rays starting from points distributed along the position of the southern squall line at 3:27 hr were calculated for a propagation time corresponding to the approximate arrival time of the meteotsunami at the location of the N3 platform. The initial propagation direction was assumed to coincide with the direction of the front movement. The shows a refraction pattern typical for perturbations initially propagating parallel to isobaths. Strong refraction can focus rays generated at northern and southern segments of the squall line onto the same patch of the shoreline. Note that the ray intersections are not proper caustics because the arrival time of the wave at the intersection point differs from ray to ray.

This pattern suggests that the East site might have been indeed impacted by two different "branches" of the meteotsunami, arriving nearly the same time at the East observation sites, but following two different paths. This could explain the structure seen in Figure 3, if the strengths of the meteotsunami waves coming along them were significantly different. Remarkably, this scenario is consistent with the presence of the two Proudman resonance bands associated with the southern squall (Figure (4)b). Indeed, a tube starting near the kink of the squall line should have carried a much larger wave (both because we expect a stronger forcing there and because of smaller depth) than a tube emerging from the southern tail of the squall line.

The typical outcome of evolution of relatively large perturbations is an undular bore, which might explain observations of the undular bore that disintegrated at the East site. The generic outcome of evolution of very weak perturbations is a lone soliton. Thus, the observed lone soliton could have resulted from the smaller perturbation generated the southern segment of the front. An additional argument in favor of this conjecture is the observed time lag: the southern ray goes trough deeper areas (see Figure 6) and hence this wave propagates faster and arrives earlier.

It is not difficult to identify a pair of ray tubes satisfying these conditions. Figure 6 shows an example of such a pair of ray tubes. The rays emerge from points in the Proudman resonance bands along the squall position at 3:48 hr and 4:04 hr, 

respectively, and pass over the location of the N1 and N2 sensors at a time that approximately matches the 6:00 hr arrival time reported by sensor N1 (e.g., Figure 3b).

\subsection{The vKdV equation}

The variable-coefficient KdV equation was derived by Ostrovsky and Pelinovsky (1975) to describe weakly nonlinear wave propagation along ray tubes in a shallow water environment with slowly varying depth, the width of the ray tubes is being specified by solutions of the eikonal equation. Rewritten in "time-like", or "signaling" coordinates (e.g., Osborne, 1995; Caputo and Stepanyants, 2003), the vKdV equation acquires the form

$$
\eta_{x}+\frac{(c \Delta)_{x}}{2 c \Delta} \eta+\frac{1}{c}\left(1-\frac{3}{2 h} \eta\right) \eta_{t}-\frac{h^{2}}{6 c^{3}} \eta_{t t t}=-F(\eta)
$$

adequate for describing the evolution of perturbation $\Phi(t)$ introduced at the left boundary into the still water domain $x>0$, as a time series $\eta(x, t)$ recorded by a sensor at location $x$. Here, the subscripts represent partial derivatives, $x$ is the alongchannel coordinate, $t$ is the time, $\eta$ is the free surface elevation, $F$ is a dissipation/growth forcing term, $c=\sqrt{g h}$, and $\Delta$ the channel width. The "boundary" Cauchy problem for equation 3 is written as

$$
\begin{gathered}
\eta_{x}+\frac{1}{c}(1-\alpha \eta) \eta_{t}-\beta \eta_{t t t}+\frac{1}{2} \frac{\delta_{x}}{\delta} \eta=-F(\eta), \\
\alpha=\frac{3}{2 h} ; \quad \beta=\frac{h^{2}}{6 c^{3}} ; \quad \delta=c \Delta
\end{gathered}
$$

with boundary and initial conditions

$$
\begin{cases}\eta(x, t)=\Phi(t) \quad \text { at } x=0 \\ \eta(x>0, t=0)=0 & \text { at } t=0 \text { and } x>0 .\end{cases}
$$

Several simple transformations (see details, e.g., Caputo and Stepanyants, 2003) bring the equation to a standard normal form. The inhomogeneous term, which describes the effect of the variable depth and width of the ray tube, can be eliminated by substitution a flux-like quantity

$$
\zeta=\eta \delta^{1 / 2}, \eta=\zeta \delta^{-1 / 2}
$$

shifting the time axis to the local time $\bar{t}$

$$
\bar{t}=t-\int_{0}^{x} \frac{d x^{\prime}}{c}, \bar{x}=x
$$


344

and using a scaling transformation based on the forcing in the initial condition 6

$$
\Phi(\bar{t})=A \phi\left(\frac{\bar{t}}{T}\right), \quad s=\frac{A}{T} \int_{0}^{\bar{x}} \frac{\alpha d s}{c \delta^{1 / 2}}, \quad \theta=\frac{\bar{t}}{T}, \quad \zeta=A q,
$$

obtains the non-dimensional form

$$
\begin{gathered}
q_{s}-\frac{1}{2}\left(q^{2}\right)_{\theta}-\frac{1}{U^{2}} q_{\theta \theta \theta}=-\frac{1}{R} \mathscr{F}(q) \\
\left\{\begin{array}{l}
q(0, \theta)=\phi(\theta) \\
q(s>0,0)=0
\end{array}\right.
\end{gathered}
$$

where

$$
U^{2}=\frac{\alpha A T^{2}}{9 \beta c \delta^{1 / 2}}, \quad R=\frac{3 \alpha A^{2}}{c \delta^{1 / 2} T}, \quad \mathscr{F}(q)=\delta^{1 / 2} F\left(\zeta \delta^{-1 / 2}\right),
$$

where $A$ is the amplitude and $T$ is the time scale of the initial perturbation $\Phi ; L=c T$ is the spatial scale of the perturbation; $U$ is the Ursell parameter; and $\theta$ is the normalized local time.

Several expressions for the dissipation term $\mathscr{F}$ are discussed in Caputo and Stepanyants (2003), corresponding to Rayleigh, (Pelinovsky et al., 1993; Holloway et al., 1997), Chezy (Pelinovsky et al., 1993; Holloway et al., 1997, 1999) and Reynolds formulations. For simplicity, we use here the Rayleigh formulation (intermediate strength, e.g., Caputo and Stepanyants, 2003),

$$
\mathscr{F}(q)=\frac{3}{4} \frac{v}{c h^{2}} q
$$

\subsection{Numerical tests}

Numerical simulations focused on testing the hypothesis that the observed peculiar pattern of the meteotsunami shown in Figure 3 can be the result of a "superposition" of two waves with significantly different magnitudes separated in time that emerge from the two well-separated tips of the southern squall line.

The $v K d V$ equation was integrated over the two ray tubes shown in Figure 6a. Because the northern tip of the squall line is near the kink and water depth there is relatively shallow we have all grounds to assume the perturbation produced by that 
segment to be strong. In contrast, the southern tip of the squall is expected to produce a weak wave. The simulations were run with Gaussian initial perturbations of the form

$$
q_{n}(0, \theta)=a_{n} \sqrt{e} \exp \left[-\frac{1}{2}\left(\frac{\theta-\theta_{0}}{\gamma_{n}}\right)^{2}\right], n=1,2
$$

where the amplitude $a_{n}$ and width $\gamma_{n}$ of each perturbation can be set to represent weaker or stronger perturbations. In principle, one could pursue a full-blown inverse modeling approach that minimizes some measure of the difference between numerical results and observations. However, because the direct model is not well defined (for example, we know nothing about the bottom friction), and because the goal of this study is a proof of concept, the numerical tests were limited to a few trials (order of 50 runs) necessary to find a suitable example.

Numerical tests show that two perturbations, one relatively strong $\left(a_{1}=1.0 \mathrm{~m}\right.$, and $\left.\gamma_{1}=10 \mathrm{~min}\right)$ coming from the northern (kink) tip of the squall line, the other smaller and shorter $\left(a_{1}=0.6 \mathrm{~m}\right.$, and $\left.\gamma_{1}=3 \mathrm{~min}\right)$, coming from the southern tip (see tubes in Figure 6a), would arrive at the East site nearly simultaneously, producing a time series pattern very similar to that observed. Figures 7-8 show the evolution of the perturbations along the rays. While the large perturbation steepens slowly and begins to disintegrate near the 10-m isobath, producing a large number of emerging solitons (undular bore), the weaker perturbation becuse of the stronger dispersion in deeper water disintegrates earlier (near the 20-m isobath), and generates a single soliton which breaks away quickly as it shoals.

The key robust feature of the ray pattern is that the rays emanating from both the northern and southern tips of the front overlap in the nearshore. Assuming that the two rays overlapped in approximately 25-m depth allows one to superpose the two signals at this depth and then from that allows them to evolve and disintegrate as a single entity. Figure (9) shows the result of integrating the $\mathrm{vKdV}$ equation for this scenario. The structure of the reconstructed signal at N1 is qualitatively similar to observations. There are some discrepancies in size, for example the lone soliton is larger than observed, but these are due to the use of generic description of dissipation processes and our guess of the initial amplitude. The reason for the discrepancy in the arrival time (observations: 6:00 hr; simulations 5:30 hr) is due in part to the inexact method used for identifying the ray tubes, and in part to the difference between linear and nonlinear propagation times. Ray calculations are linear; the $\mathrm{vKdV}$ perturbations are propagate with velocity $>\sqrt{g h}$, with the difference depending on their nonlinearity. This effect is clearly seen in Figure (8): for example, for the larger perturbation (Figure 8a), taking the arrival time to be somewhere in span of the solibore puts the nonlinear perturbation between 7 -min and 17-min ahead of the linear estimate (origin of the time axis). 
These discrepancies could relatively easily be tuned off by adjusting the generic dissipation and using a more accurate process for selecting the rays. However, such an effort not only seems pointless in the context of this study, but could create a false impression that we can indeed quantitatively reproduce the observed meteotsunami. The goal of the simulations was to reveal the physics underpinning the observed pattern and we believe that the above simulations have achieved it.

\section{Summary and discussion}

This study reports observations of the nearshore transformation of a meteotsunami on the Atchafalaya shelf, Louisiana on March 7, 2008. The event was captured by a large, high-resolution instrument array that included pressure sensors, current profilers, turbidity sensors, salinity and temperature, and others), which provided an uniquely detailed description of the meteotsunami transformation, including the disintegration into solitary wave trains, dissipation and interaction with the muddy bed, as well as associated sediment transport and bed reworking processes.

The analysis presented here focuses on an intriguing aspect of this transformation: the presence of very robust, ubiquitous and persistent lone soliton followed by an undular bore, observed at all the locations of the experiment (spanning over 150 $\mathrm{km}$ in the alongshore). An accurate quantitative modeling of emergence of this pattern for the specific conditions of the experiment would have required inaccessible detailed meteorological data over sea, and thus is not possible. In principle, extensive backward high-resolution numerical simulations covering scales spanning several orders of magnitude could allow one to reconstruct the initial conditions of the observed meteotsunami but the resulting accuracy would have been questionable, while such an attempt would have required a massive simulations. Here we aimed at understanding of the physical mechanisms resulting in the emergence of such a pattern and elucidating whether it is unique or generic phenomenon.

We hypothesize that the observed lone soliton and solibore were produced by two overlapping meteotsunami waves of different provenance. Assuming that the meteotsunami was generated through Proudman resonance, an analysis of the available radar reflectivity suggests that two waves might have impacted the East site of the experiment, emerging independently from the two tips of the southern segment of the squall line. Because the northern tip was associated with a strong kink in the squall line (indicative of strong rotation and tornado activity), it is expected that the corresponding wave was larger that that generated by the weaker, southern tail of the squall. As the number of solitons resulting from the disintegration of a perturbation depends on the strength of the perturbation, (e.g., magnitude of the Ursell parameter), the weaker wave could explain the presence of the lone solitons. Our numerical simulations, combining a simple ray tracing method with vKdV integrations 
of simple Gaussian initial perturbations, support the hypothesis. An additional strong argument in its favor is the observed time lag: the southern ray goes trough deeper areas, as shown in Fig 6b, this wave propagates faster and arrives earlier in rough accordance with the observations. This gives us grounds to believe that we have revealed the physics underpinning the observed unusual meteotsunami pattern.

Is such a pattern unique, rare, or common for meteotsunamis? Because lone solitons are in fact the degenerate form of weak solibores, and solibore (meteo)tunamis have been observed before, both forms of perturbations should be quite common. However, occurrences of two such perturbations collocated have never been reported before. In hindsight, such structures should be expected. Our simulations show lone solitons to be generic result of the disintegration of the weak meteotsunami segments refracting and shoaling over the shelf. The existence of such weak waves is almost guaranteed by the variability of the forcing along a squall line. The variability of the front strength and direction could result in several rays arriving at the same point and thus we could expect even more complicated patterns made of one or more generic lone solitons and one or more undular bores. The potential diversity of possible patterns is huge, but lone solitons are expected to be their common feature.

This study used only a small fraction of the data collected in 2008 on the Atchafalaya shelf. While the observations do not address questions related to the large-scale propagation of the meteotsunami, they provide unprecedented insight into its nearshore transformation, including the poorly understood interaction between such waves and the muddy environment of the area. This question will be the subject of future research.

\section{Acknowledgements:}

This research was supported by Office of Naval Research grants N00014-13-1-0620, and NSF Grant CMMI-1208147 “Interaction of Tsunamis with Short Waves and Bottom Sediment - Numerical and Physical Modeling." The experimental work was funded by Office of Naval Research grants N00014-10-1-0363, N00014-10-1-0805, and N00014-11-1-0269. The authors are grateful for the thoughtful advice and suggestions provided by two anonymous referees.

\section{References}

Bechle, A. J., D. A. R. Kristovich, and C. H. Wu (2015). Meteotsunami occurrences and causes in Lake Michigan, J. Geophys. Res., 120, doi:10.1002/2015JC011317. 
Benjamin S.G., S.S. Weygandt, J.M. Brown, M. Hu, C.R. Alexander, T.G. Smirnova, J.B. Olson, E.P. James, D.C. Dowell, G.A. Grell, H. Lin, S.E. Peckham, T.L. Smith, W.R. Moninger, J.S. Kenyon, and G.S. Manikin (2016). A North American Hourly Assimilation and Model Forecast Cycle: The Rapid Refresh. Mon. Wea. Rev., 144, 1669-1694, doi:10.1175/MWRD-15-0242.1

Bjørkavåg, M., and H. Kalisch (2011). Wave breaking in Boussinesq models for undular bores. Physics Letters A, 375(14), 1570-1578. http://doi.org/10.1016/j.physleta.2011.02.060

Borrero J.C., P.J. Lynett, and N. Kalligeris (2015). Tsunami currents in ports. Phil. Trans. R. Soc. A 373: 20140372. http://dx.doi.org/10.1098/rsta.2014.0372

Caputo, J.-G., and Y.A. Stepanyants (2003). Bore formation, evolution and disintegration into solitons in shallow inhomogeneous channels. Nonlin. Proc. Geophys., European Geosciences Union (EGU),10 (4/5), 407-424.

Chan, I-C., and P. L.-F. Liu (2012). On the runup of long waves on a plane beach, J. Geophys. Res., 117, C08006, doi:10.1029/2012JC007994.

Chao, Y. Y. (1970). The theory of wave refraction in shoaling water, including the effects of caustics and the spherical earth. New York, N.Y.: New York University, School of Engineering and Science, Dept. of Meteorology and Oceanography, http://catalog.hathitrust.org/Record/007254345

Chao, Y. Y. (1972). Refraction of ocean surface waves on the continental shelf. Offshore Technology Conference. doi:10.4043/1616-MS

Choi B.H. , E. Pelinovsky, K.O. Kim, and J.S. Lee (2003). Simulation of the trans-oceanic tsunami propagation due to the 1883 Krakatau volcanic eruption, Nat. Hazards Earth Syst. Sci. (3), 321-332.

Churchill, D.D., S.H. Houston, and N.A. Bond (1995). The Daytona Beach Wave of 3-4 July 1992: A Shallow-Water Gravity Wave Forced by a Propagating Squall Line, Bul. Am. Met. Soc. 76(1), 21-32.

Engelstad, A. T. Janssen, T.H.C. Herbers, G. van Vledder, S. Elgar, B. Raubenheimer, L. Trainor, and A. Garcia-Garcia (2013). Wave evolution across the Louisiana shelf, Cont. Shelf Res. 52, 190-202.

Egbert, G.D., and S.Y. Erofeeva (2002). Efficient Inverse Modeling of Barotropic Ocean Tides. J. Atmos. Oceanic Technol., 19, 183-204. doi: http://dx.doi.org/ 10.1175/1520-0426(2002)019<0183:EIMOBO>2.0.CO;2

El, G.A., R.H.J. Grimshaw, and N.F. Smyth (2009). Transcritical shallow-water flow past topography: finite-amplitude theory. Journal of Fluid Mechanics, 640, pp 187-214 doi:10.1017/S0022112009991315 
El, G.A., R.H.J. Grimshaw, and W.K. Tiong, (2012). Transformation of a shoaling undular bore. J. Fluid Mech., 709, 371-395. http://doi.org/10.1017/jfm.2012.338

Engelbrecht,J. K. , V. E. Fridman, and E. N. Pelinovsky, Nonlinear Evolution Equations, Longman/Wiley, New York, 1988]

Ewing, M., F. Press, and W.J. Donn (1954). An explanation of the Lake Michigan wave of 26 June 1954, Science, 120, 684-686.

Greenspan, H. P. (1956). The generation of edge waves by moving pressure disturbances, J. Fluid Mech., 1, 574-592.

Grimshaw, R. (2007). Solitary waves propagating over variable topography. In A. Kundu (Ed.), Tsunami and Nonlinear Waves, Springer, 49-62.

Griswold, G. M. (1963), Numerical calculation of wave refraction, J. Geophys. Res., 68(6), 1715-1723, doi:10.1029/JZ068i006p01715.

Grue, J., E. N. Pelinovsky, D. Fructus, T. Talipova, and C. Kharif (2008). Formation of undular bores and solitary waves in the Strait of Malacca caused by the 26 December 2004 Indian Ocean tsunami, J. Geophys. Res., 113, C05008, doi:10.1029/ 2007JC004343.

Hardy, J. W., \& Hsu, S. A. (1997). A Climatology of winter cyclogenesis intensity in the northwest Gulf of Mexico. Natl Weather Dig, 22, 3-7.

Hibiya, T. and K. Kajiura (1982). Origin of “Abiki” phenomenon (kind of seiches) in Nagasaki Bay, J. Oceanogr. Soc. Japan, 38, 172-182.

Holden, H., K.H. Karlsen, K.-A. Lie, and N.H. Risebro (2010). Splitting Methods for Partial Differential Equations with Rough Solutions, Analysis and MATLAB programs, EMS Series of Lectures in Mathematics, A. Ranicki ed., University of Edinburgh, U.K.

Holloway P.E., E. Pelinovsky, T.G. Talipova, and B. Barnes (1997). A non- linear model of internal tide transformation on the Australian north west shelf, J. Phys. Oceanogr., 27, 871-896.

Holloway P.E., E. Pelinovsky, T.G. Talipova (1999). A generalized Korteweg-de Vries model of internal tide transformation in the coastal zone, J. Geophys. Res., 104, 18 333-18 350.

Horvarth, K., and I. Vilibić (2014). Atmospheric mesoscale conditions during the Boothbay meteotsunami: a numerical sensitivity study using a high-resolution mesoscale model, in, Meteorological Tsunamis: The U.S. Coast and other coastal regions, Vilibić et al. eds. Nat. Haz. (74), 55-74. 
Jaramillo, S., A. Sheremet, M. Allison, A, Reed, and K.T. Holland (2009). Wave-mud interÂactions over the muddy Atchafalaya subaqueous clinoform, Louisiana, USA: Wave-driven sediment transport, J. Geophys. Res., 114, C04002, doi:10.1029/ 2008JC004821.

Johnson, R.S. (2008). On the development of a solitary wave moving over an uneven bottom. Mathematical Proceedings of the Cambridge Philosophical Society, 73(01), 183. http://doi.org/10.1017/S0305004100047605

Kamchatnov, M., Y.-H Kuo, T.-C. Lin, T.-L. Horng, S.-C. Gou, R. Clift, and R.H.J. Grimshaw (2012). Undular bore theory for the Gardner equation. Phys. Rev. E, 86(3), 036605. http://doi.org/10.1103/PhysRevE.86.036605

Kharif, C., E. Pelinovsky, and A. Slunyaev (2009). Rogue waves in the ocean. Springer Series: Advances in Geophysical and Environmental Mechanics and Mathematics.

Liu, P.L.-F., Y.S. Park and E.A. Cowen (2007). Boundary layer flow and bed shear stress under a solitary wave. J. Fluid Mech., 574, pp 449-463 doi:10.1017/S0022112006004253.

Lynett, P. J., J. Borrero, S. Son, R. Wilson, and K. Miller (2014). Assessment of the tsunami-induced current hazard, Geophys. Res. Lett., 41, 2048-2055, doi:10.1002/ 2013GL058680.

Madsen, P. A., D. R. Fuhrman, and H. A. Scha“ffer (2008), On the solitary wave paradigm for tsunamis, J. Geophys. Res., 113, C12012, doi:10.1029/2008JC004932.

Mercer, D., J. Sheng,, R.J. Greatbatch, and J. Bobanović (2002). Barotropic waves generated by storms moving rapidly over shallow water, J. Geophys. Res., 107(C10), 3152, doi:10.1029/2001JC001140.

Monserrat, S. I. Vilibić, and A. B. Rabinovich (2006). Meteotsunamis: atmospherically induced destructive ocean waves in the tsunami frequency band, Nat. Hazards Earth Syst. Sci., 6, 1035-1051.

Osborne A.R. (1995). The inverse scattering transform: tools for the nonlinear Fourier analysis and filtering of ocean surface waves, Chaos, solitons and fractals, 5, 2623-2637.

Ostrovsky L.A., and E.N. Pelinovsky (1975). Refraction of nonlinear ocean waves in a beach zone. Izv. Atmos. Ocean Phys. $11,37-41$.

Ostrovsky L.A., and V.I. Shrira (1976). Instability and self-refraction of solitons Sov.Phys. JETP, 44, 738-743.

Paxton, C.H. and D.A. Sobien (1998), Resonant Interaction between an Atmospheric Gravity Wave and Shallow Water Wave along Florida's West Coast, Bul. Am. Met. Soc. 79(12), 2727-2732.

Pelinovskii, E.N. (1971). The evolution of a solitary wave in a nonhomogeneous medium, J. Appl. Mech. Tech. Phys. 12, $853-858$. 
Pelinovsky E.N., Y.A. Stepanyants, and T.G. Talipova (1993). Nonlinear dispersion model of sea waves in the coastal zone, J. Korean Soc. Coastal Ocean Eng., 5, 307-317.

Pelinovsky, E.N., B.H. Choi, T. Talipova, S.B. Woo, D.C. Kim (2010). Solitary wave transformation on the underwater step: Asymptotic theory and numerical experiments, Applied Math. Comp. 217, 1704-1718.

Proudman, J. (1929). The effects on the sea of changes in atmospheric pressure, Geophys. Suppl. Mon. Notices R. Astr. Soc., 2(4), 197- 209 .

Ruppert J.H. Jr and L.F. Bosart (2014). A Case Study of the Interaction of a Mesoscale Gravity Wave with a Mesoscale Convective System. Mon. Wea. Rev., 142, 1403-1429. doi: http://dx.doi.org/10.1175/MWR-D-13-00274.1

Safak, I., A. Sheremet, M.A. Allison, and T.-J. Hsu (2010). Bottom Turbulence on the Muddy Atchafalaya Shelf, Louisiana, USA, J. Geophys. Res., 115, C12019, doi:10.1029/ 2010JC006157, 2010.

Sahin, C., I. Safak, A. Sheremet, and A. J. Mehta (2012). Observations on cohesive bed reworking by waves: Atchafalaya Shelf, Louisiana, J. Geophys. Res., 117, C09025, doi:10.1029/2011JC007821.

Šepić, J., I. Vilibić, and N. Strelec Mahović (2012). Northern Adriatic meteorological tsunamis: Observations, link to the atmosphere, and predictability, J. Geophys. Res., 117, C02002, doi:10.1029/2011JC007608.

Šepić, J., I. Vilibić,, A.B. Rabinovich, and S. Monserrat (2015). Widespread tsunami-like waves of 23-27 June in the Mediterranean and Black Seas generated by high-altitude atmospheric forcing, Sci. Rep. 5, Article No. 11682, doi: 10.1038/srep11682.

Sergeeva, A., E. Pelinovsky, and T.G. Talipova, (2011). Nonlinear random wave field in shallow water: variable Korteweg-de Vries framework. Nat. Hazards Earth Syst. Sci., 11(2), 323-330. http://doi.org/10.5194/nhess-11-323-2011.

Tian, M., A. Sheremet, J.M. Kaihatu, and G. Ma (2015). On the Shoaling of Solitary Waves in the Presence of Short Random Waves. J. Phys. Oceanogr., 45, 792-806.

Thompson, P. G. Mitchum, C. Vonesch, and J. Li (2013). Variability of winter storminess in the eastern united states during the twentieth century from tide gauges. J. Climate, 26, 9713-9726.

Vilibić, I., S. Monserrat, and A.B. Rabinovich (2014). Meteorological Tsunamis: The U.S. East Coast and Other Coastal Regions, Natural Hazards, Volume 74, No. 1.

Whitham G.B., 1973, Linear and Nonlinear Waves, Pure and Applied Mathematics: A Wiley Series of Texts, Monographs and Tracts. 


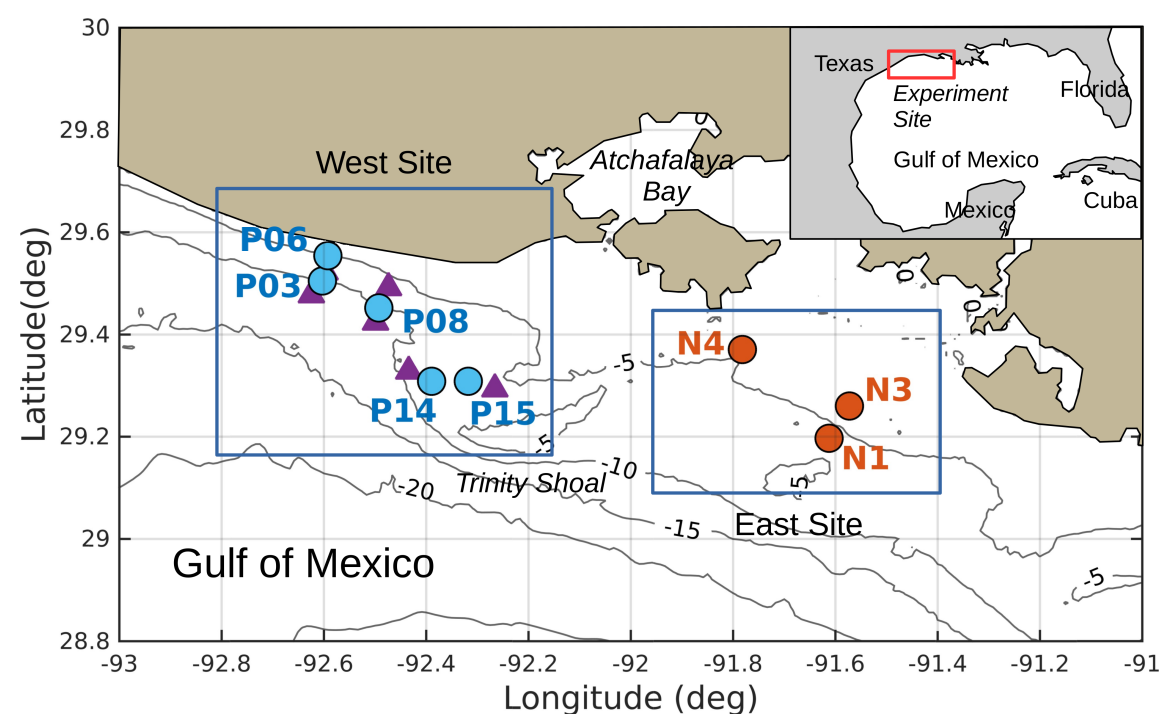

Fig. 1: Experiment site. The West site array included, among other instruments, pressure sensors (blue circles) and pressure/current sensors (violet triangles). The East site array comprised four platforms (red circles, three shown).
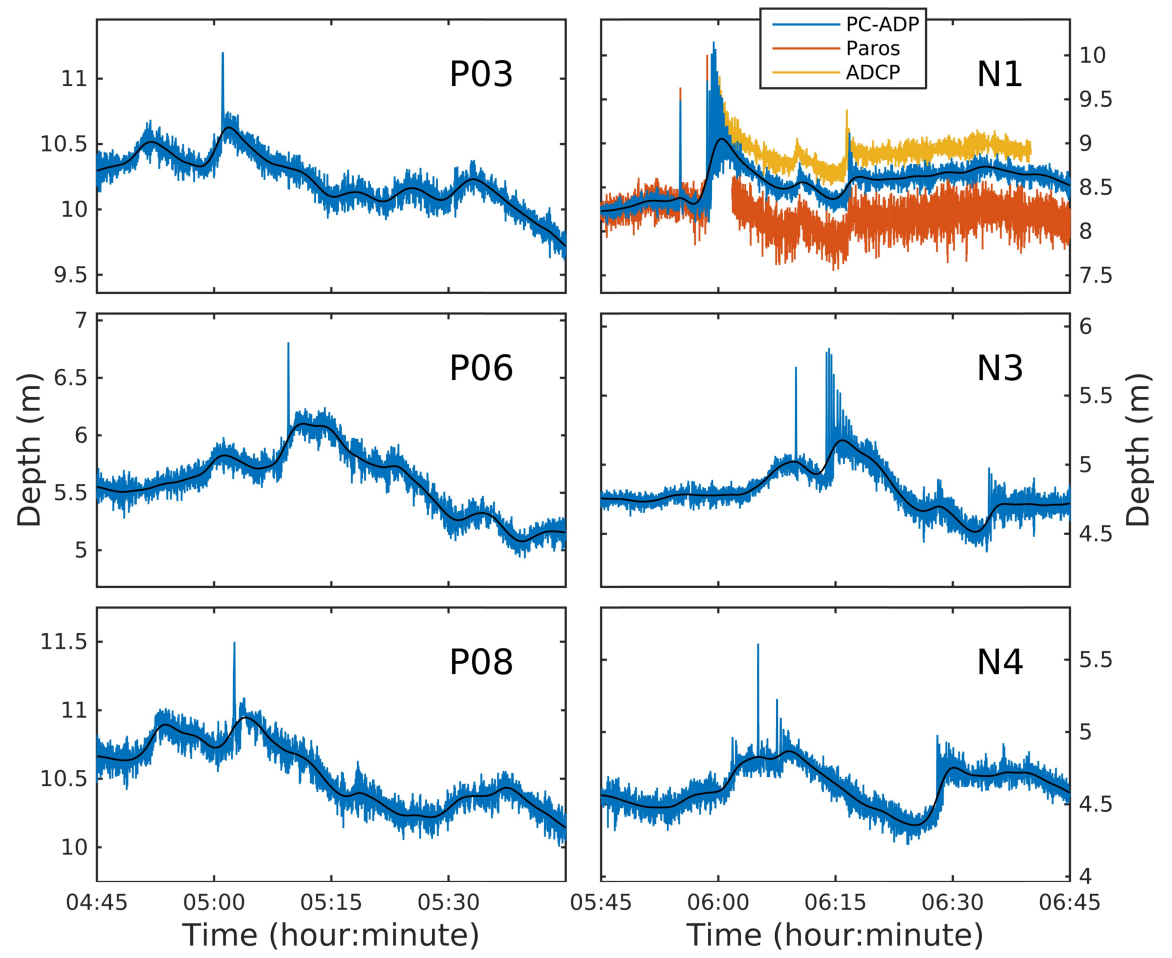

Fig. 2: Examples of de-tided time series of pressure (converted to depth) recorded at six instruments in the morning of March 7, 2008. Left: West site. Right: East site. See Figure 1 for the locations of the instruments. Lone solitons are evident (e.g., marked with an arrow on the P06 and N3 panels). Black line marks the mean water level (low-pass filtered time series). 

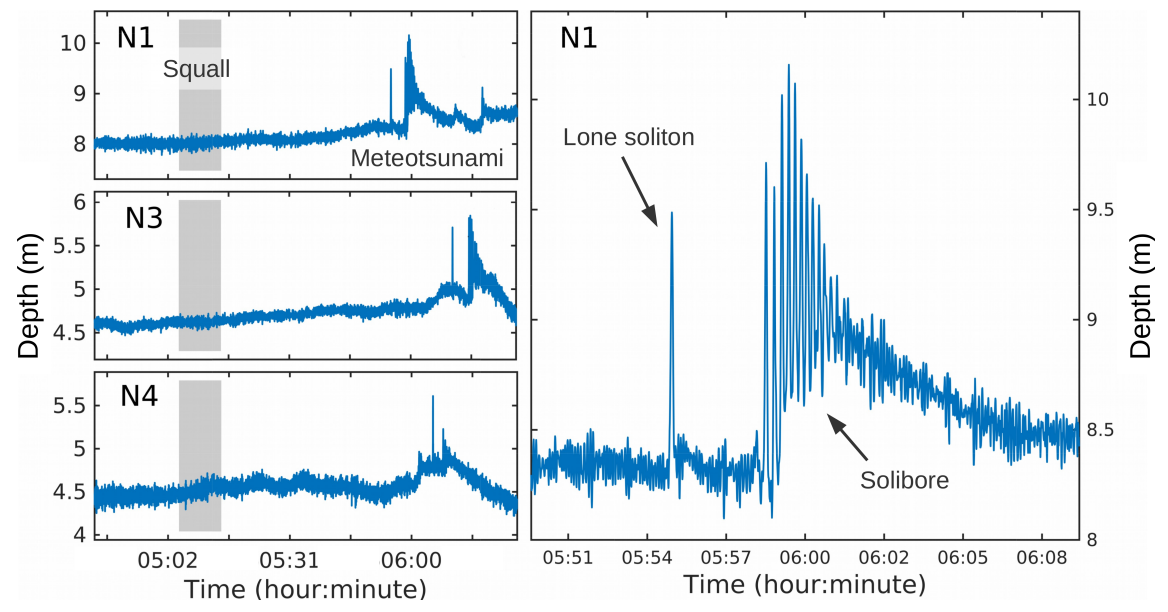

Fig. 3: Pressure time series recorded at the East site. Left: Overview, including the time interval of the squall passage. Right: Detail of the depth time series recorded at N1, showing the lone soliton and the solibore edge of the meteotsunami.

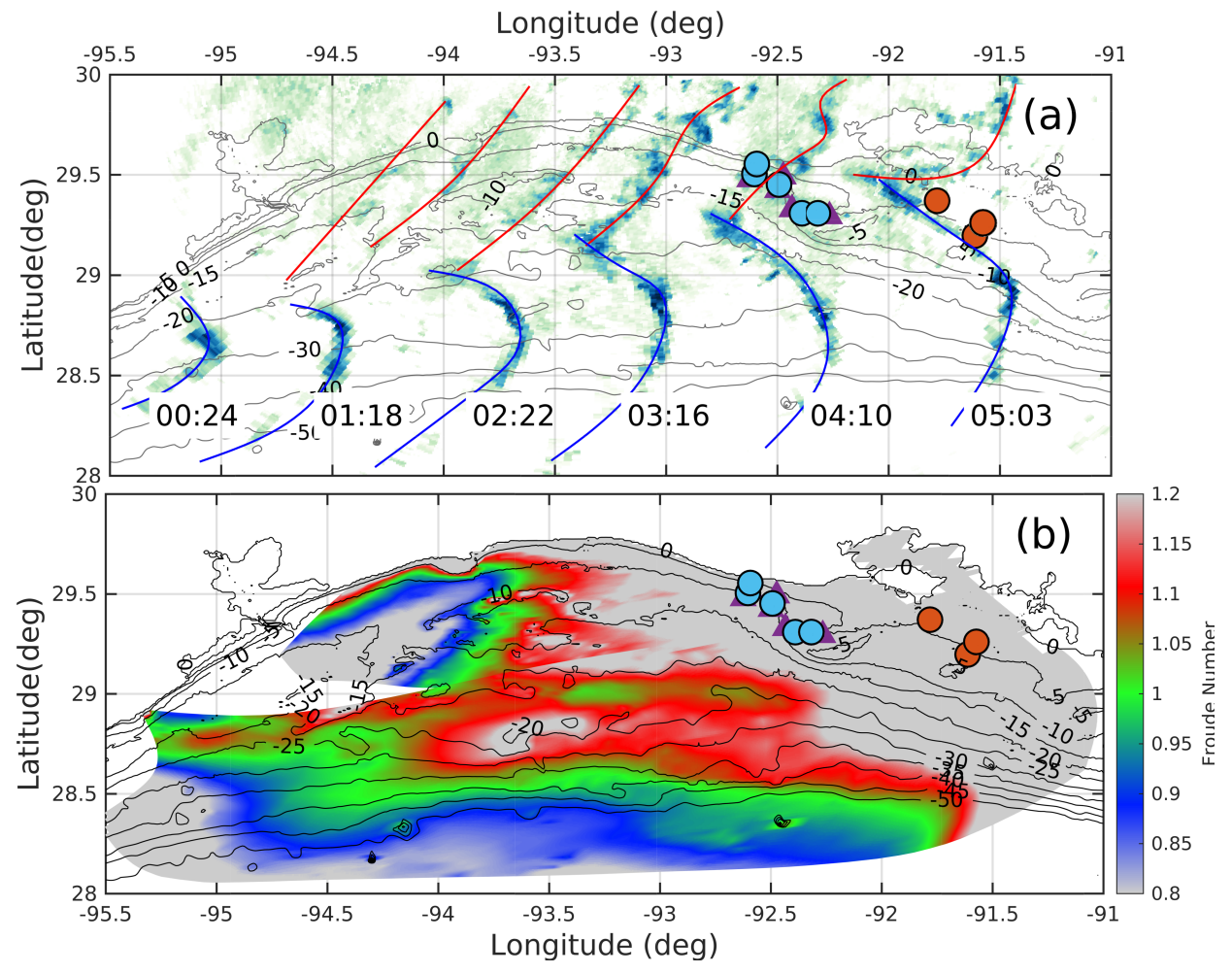

Fig. 4: Analysis of the March 7, 2008 atmospheric perturbation that generated the meteotsunami. a) Successive positions of the squall lines, as identified by radar reflectivity maps (see text for details of sources and processing). The red and blue lines are smoothed estimates (manually digitized) of the position of the two fronts (warm - red and cold - blue), and are used in this study to estimate the position of the squalls associated with the fronts. The corresponding record time is given at the bottom of the panel. b) Froude number values estimated based on the digitized position of the squall line cor. Proudman resonance is effective for $0.95<F r<1.05$ (green dot domain). 


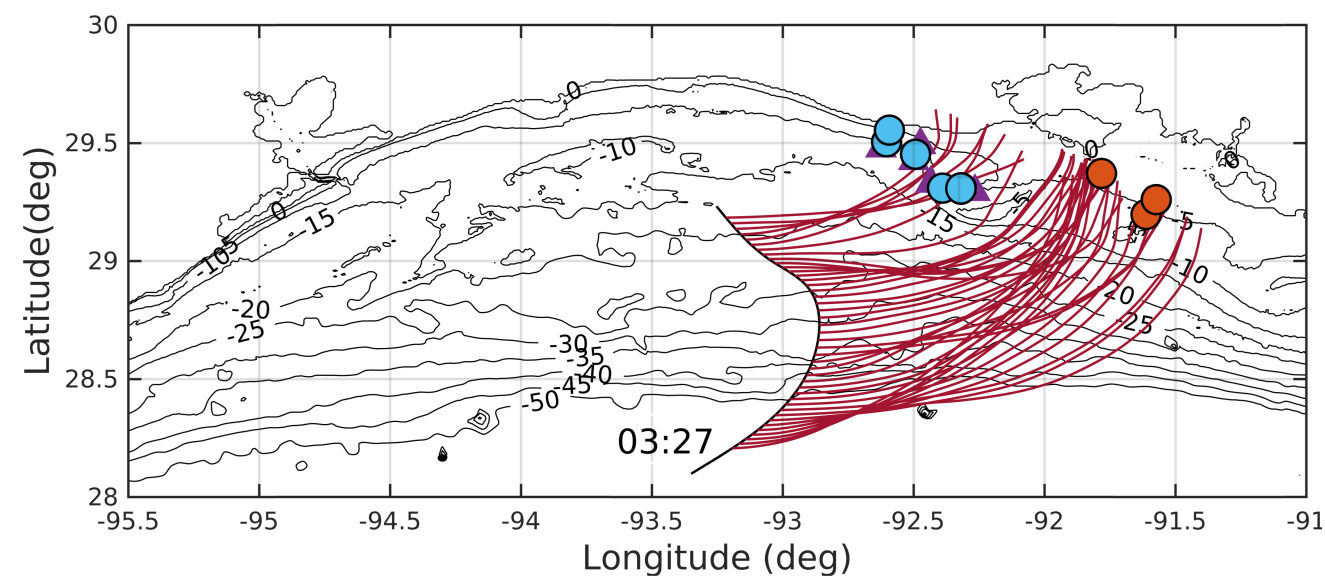

Fig. 5: Example of ray calculation starting from the southern squall line (blue lines in Figure 4a), at the position of the squall line 3:27 hr on March 7, 2008. Initial rays direction is defined as the estimated direction of the squall motion. The example illustrates the typical ray convergence pattern generated by the nearly along-isobath propagation of the atmospheric perturbation.
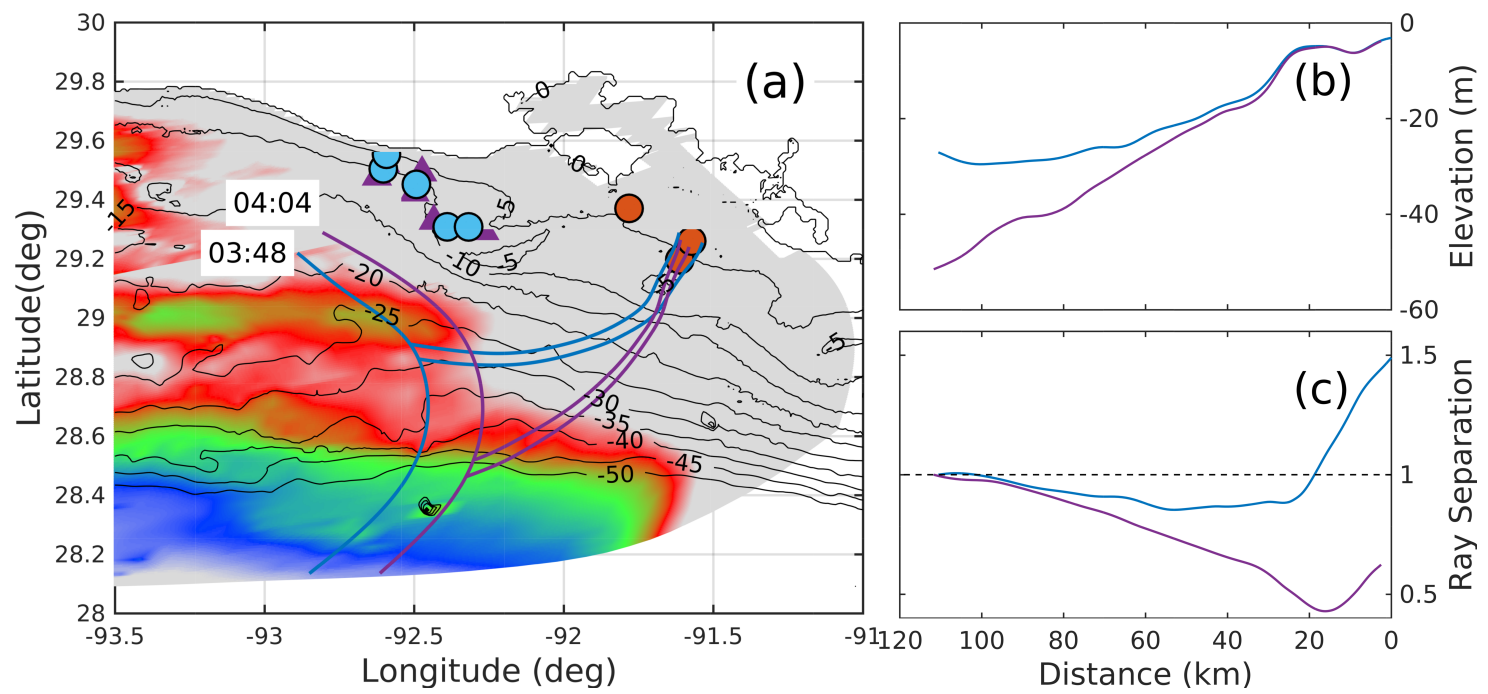

Fig. 6: Ray geometry used for the vKdV model. a) Ray tubes emerging from the northern and southern segments of the southern squall line (blue lines in Figure 4); b) Bathymetry profiles along the the ray paths (blue - North tube; purple - South tube); c) Ray tube cross-section (width). In panels b-c) the distance refers to the position of sensor N1, East site. 


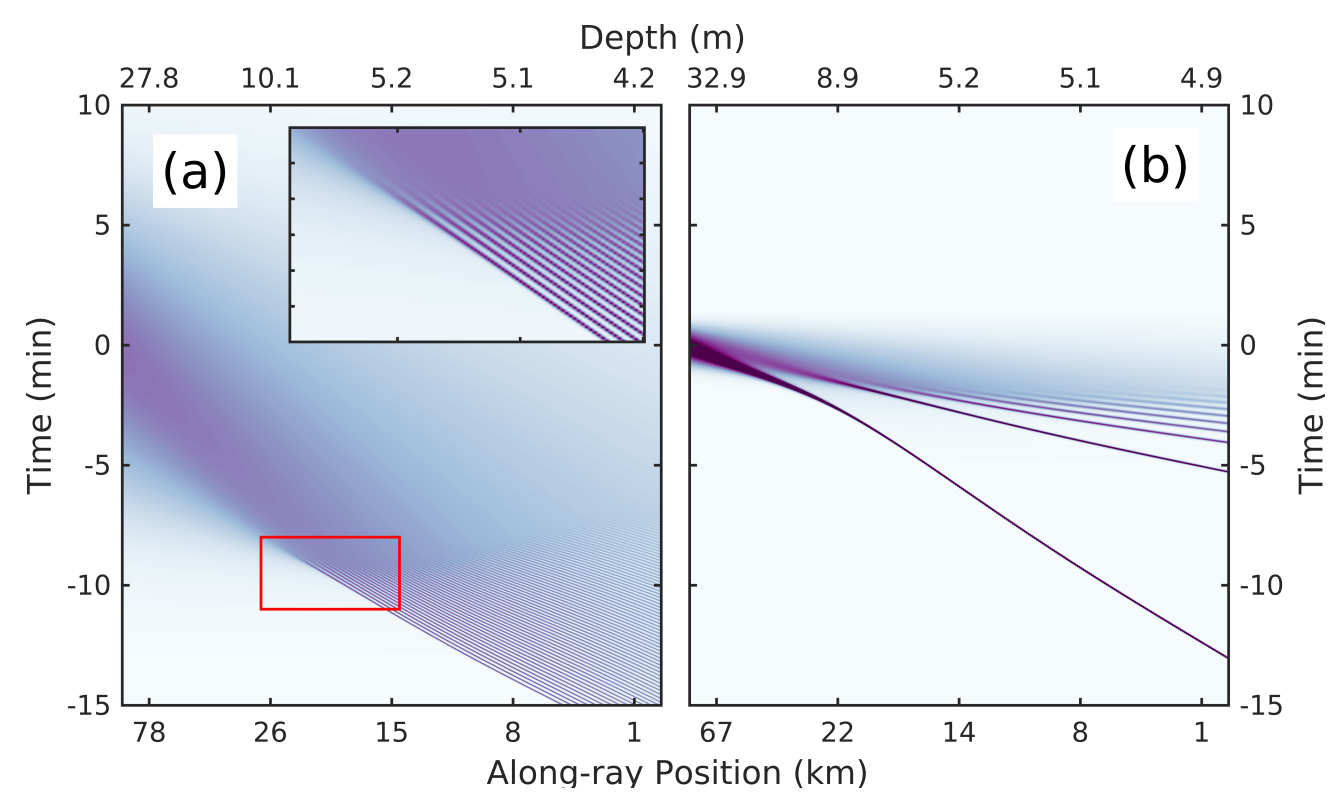

Fig. 7: Overview of the vKdV (equation 9) representation of the independent nonlinear evolution of two Gaussian perturbations: a) A strong perturbation (10-min time scale; 1.0-m initial height) propagating via the North ray tube (blue lines in Figure 6). Inset: detail of the fine structure of the disintegration process corresponding to the red box. b) A weak perturbation (3-min time scale; 0.6-m initial height) propagating along the South ray tube (purple lines in Figure 6). The perturbations do not overlap. The distance is given with respect to the position of sensor N1, East site (see also Figure 6a). The time axis is given in the "linear arrival time" coordinates, equation (8); the origin corresponds to the arrival time of the linear estimate. Note that the nonlinear perturbations arrive 10 to 20 min earlier than the linear estimate.

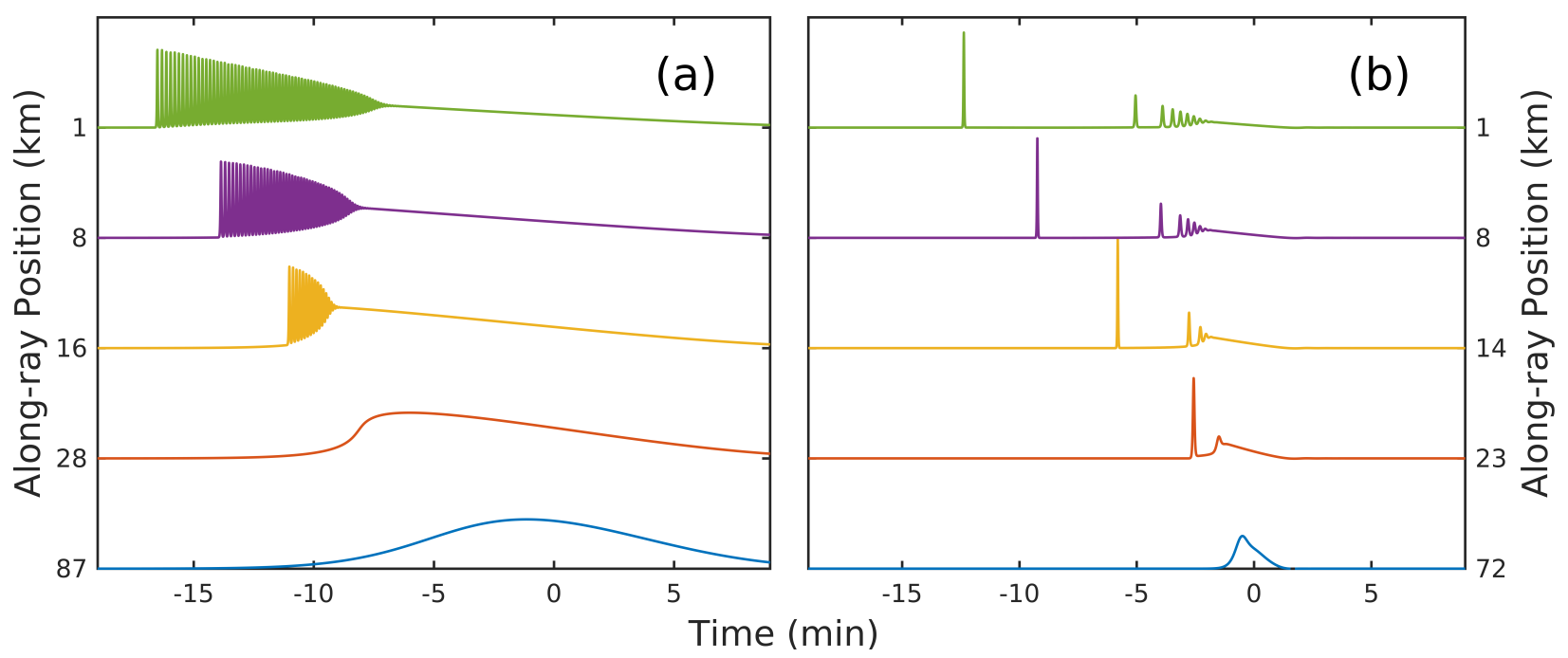

Fig. 8: Snapshots of time series corresponding to the two Gaussian perturbations (see Figure 7). a) Wave propagating along the North tube (blue lines in Figure 6); and b) wave propagating along the South ray tube (purple lines in Figure 6). The distance is given with respect to the position of sensor N1, East site. The time axis is given in the "linear arrival time" coordinates, equation (8); the origin corresponds to the arrival time of the linear estimate. 

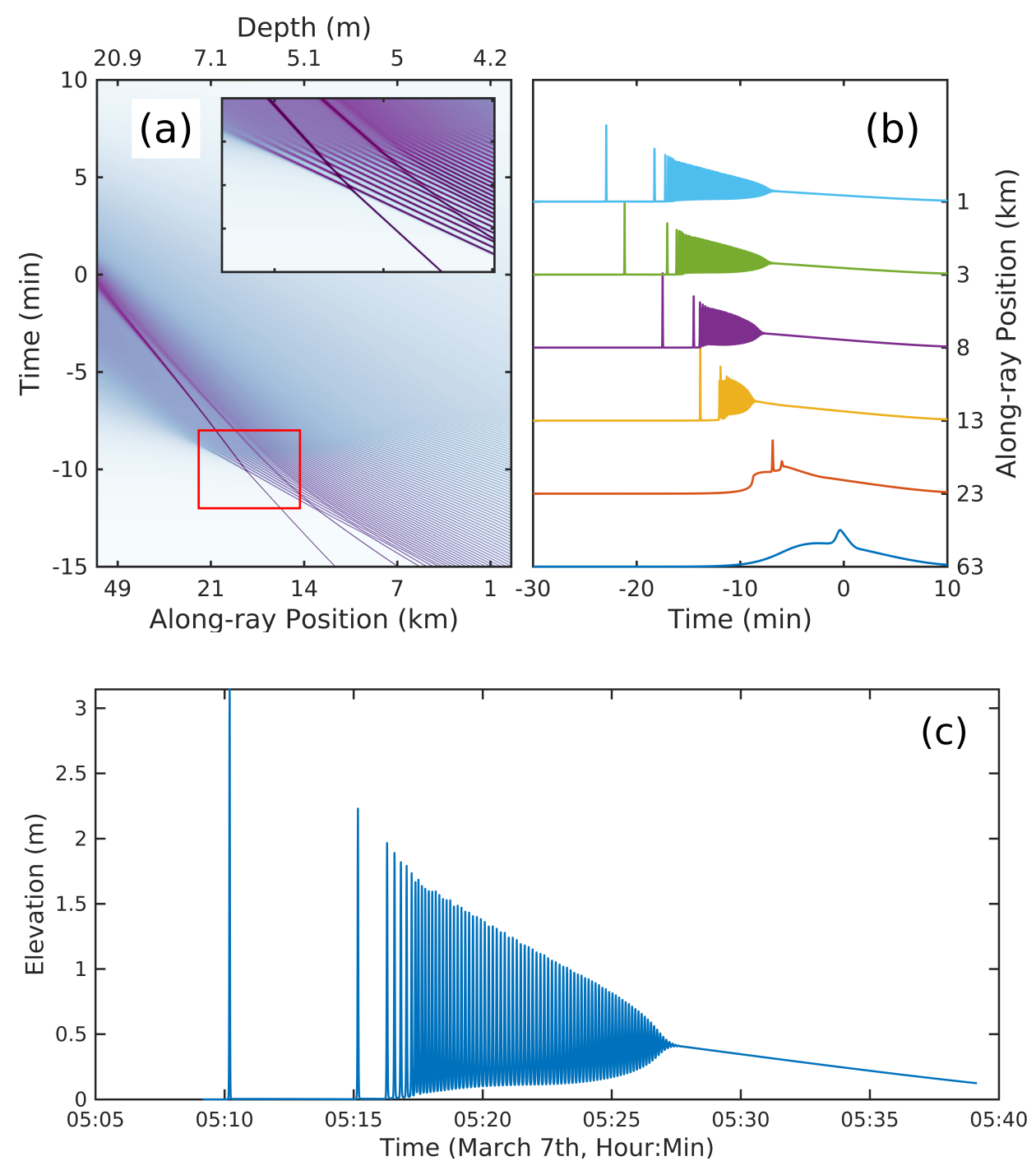

Fig. 9: a,b) Nonlinear (coupled) evolution of the two Gaussian perturbations in Figures 7-8. Inset: detail of the fine structure of the disintegration process corresponding to the red box. The initial shape of the perturbation was produced by superposing the two perturbations in Figures7-8 near the 25-m isobath (see also 6b). In panels a and b the time axis is given in the "linear arrival time" coordinates, equation (8); the origin corresponds to the arrival time of the linear estimate. c) Time series of the resulting perturbation at the approximate location of N1 sensor (last point to the right in panels b-c of Figure 6), as it would have been recorded by the sensor. The time axis is the local time at N1.

The discrepancy between the actual arrival time of the tsunami and the computed arrival time is discussed in the text. 